This item was submitted to Loughborough's Research Repository by the author.

Items in Figshare are protected by copyright, with all rights reserved, unless otherwise indicated.

\title{
A validated model of GAG deposition, cell distribution, and growth of tissue engineered cartilage cultured in a rotating bioreactor
}

PLEASE CITE THE PUBLISHED VERSION

http://dx.doi.org/10.1002/bit.22581

PUBLISHER

(C) John Wiley and Sons

VERSION

SMUR (Submitted Manuscript Under Review)

LICENCE

CC BY-NC-ND 4.0

\section{REPOSITORY RECORD}

Nikolaev, N.I., B. Obradovic, Hendrik K. Versteeg, G. Lemon, and David J. Williams. 2019. "A Validated Model of GAG Deposition, Cell Distribution, and Growth of Tissue Engineered Cartilage Cultured in a Rotating Bioreactor". figshare. https://hdl.handle.net/2134/13370. 
This item was submitted to Loughborough's Institutional Repository (https://dspace.lboro.ac.uk/) by the author and is made available under the following Creative Commons Licence conditions.

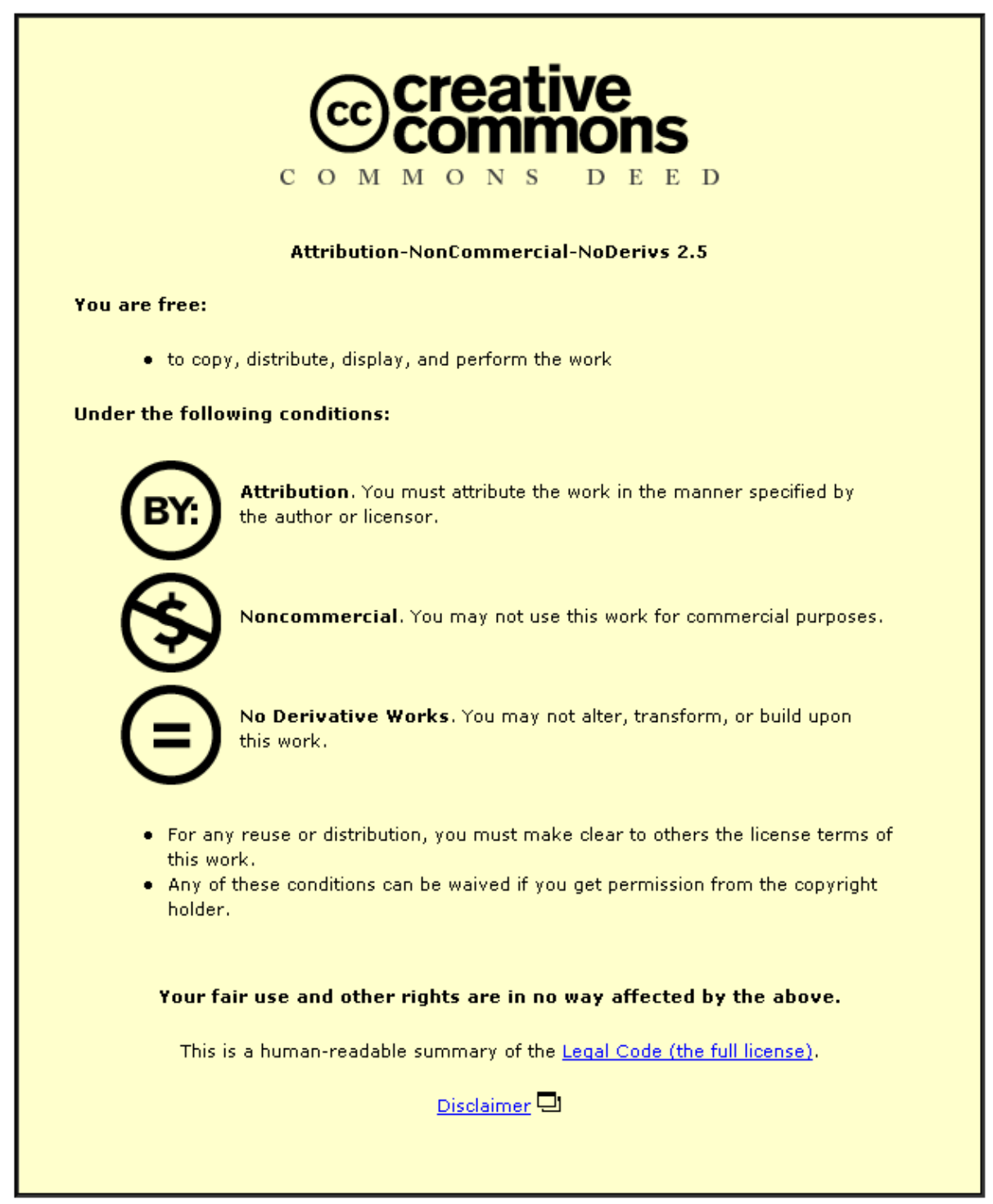

For the full text of this licence, please go to: http://creativecommons.org/licenses/by-nc-nd/2.5/ 


\section{A Validated Model of GAG Deposition, Cell Distribution and Growth of Tissue Engineered Cartilage Cultured in a Rotating Bioreactor}

\begin{tabular}{|r|l|}
\hline Journal: & Biotechnology and Bioengineering \\
\hline Manuscript ID: & 09-492.R1 \\
\hline Wiley - Manuscript type: & Article \\
\hline Key Words: & $\begin{array}{l}\text { mathematical model, cartilage tissue engineering, tissue growth, } \\
\text { glycosaminoglycan deposition, cell distribution }\end{array}$ \\
\hline
\end{tabular}

\section{S ScholarONE \\ Manuscript Central}


A Validated Model of GAG Deposition, Cell Distribution and Growth of Tissue Engineered Cartilage Cultured in a Rotating Bioreactor

\section{N.I. Nikolaev ${ }^{1}$, B. Obradovic ${ }^{2}$, H.K.Versteeg ${ }^{1}$, G. Lemon ${ }^{3}$ and D.J. Williams ${ }^{1}$}

${ }^{1}$ Wolfson School of Mechanical \& Manufacturing Engineering, Loughborough University, Loughborough LE11 3TU, UK

${ }^{2}$ Department of Chemical Engineering, Faculty of Technology and Metallurgy, University of Belgrade, Karnegijeva 4, 11000 Belgrade, Serbia

${ }^{3}$ School of Mathematical Sciences, University of Nottingham, Nottingham NG7 2RD, UK.

Short running title: A Validated Model of Cartilage Tissue Growth

Corresponding Author:

Dr. Nikolay Nikolaev

Wolfson School of Mechanical \& Manufacturing Engineering,

Loughborough University,

Loughborough

LE11 3TU, UK

Tel: +441509564889

Fax: +441509564894

Email: N.I.NIKOLAEV@lboro.ac.uk 


\section{Abstract}

In this work a new phenomenological model of growth of cartilage tissue cultured in a rotating bioreactor is developed. It represents an advancement of a previously derived model of deposition of glycosaminoglycan (GAG) in engineered cartilage by (i) introduction of physiological mechanisms of proteoglycan accumulation in the extracellular matrix (ECM) as well as by correlating (ii) local cell densities and (iii) tissue growth to the ECM composition. In particular, previously established predictions and correlations of local oxygen concentrations and GAG synthesis rates are extended to distinguish cell secreted proteoglycan monomers free to diffuse in cell surroundings and outside from the engineered construct, from large aggrecan molecules, which are constrained within the ECM and practically immovable. The model includes kinetics of aggregation i.e. transformation of mobile GAG species into immobile aggregates as well as maintenance of the normal ECM composition after the physiological GAG concentration is reached by incorporation of a product inhibition term. The model also includes mechanisms of the temporal evolution of cell density distributions and tissue growth under in vitro conditions. After a short initial proliferation phase the total cell number in the construct remains constant, but the local cell distribution is levelled out by GAG accumulation and repulsion due to negative molecular charges. Furthermore, strong repulsive forces result in expansion of the local tissue elements observed macroscopically as tissue growth (i.e. construct enlargement). The model is validated by comparison with experimental data of (i) GAG distribution and leakage, (ii) spatialtemporal distributions of cells and (iii) tissue growth reported in previous works. Validation of the model predictive capability - against a selection of measured data that were not used to construct the model - suggests that the model successfully describes the interplay of several simultaneous processes carried out during in vitro cartilage tissue regeneration and indicates that this approach could also be attractive for application in other tissue engineering systems.

Key words: mathematical model, cartilage tissue engineering, tissue growth, glycosaminoglycan deposition, cell distribution 


\section{INTRODUCTION}

Tissue engineering is one of the new strategies aiming to address the clinical problem of tissue and organ failure. One approach to tissue engineering is based on the integrated use of reparative cells, biodegradable scaffolds and bioreactor systems to cultivate functional tissue equivalents for potential clinical use (Vunjak-Novakovic and Goldstein, 2005), (Freshney et al., 2007). Scaffolds are designed to serve as a structural and logistic template for tissue development while the bioreactor should enable environmental control and support cell differentiation and functional assembly of components of extracellular matrix (ECM). Tissue engineering systems can also be used as relevant physiological models for controlled in vitro studies of cells and tissues under normal and pathological conditions. This approach is biomimetic in nature aiming to recapitulate processes during normal in vivo tissue development and promote regeneration of competent tissue equivalents capable of fully and functionally integrating with the host tissue upon implantation. Design of tissue engineering systems thus relies on knowledge and understanding of cell and tissue biology and physiology. In order to create the optimal cellular microenvironment in vitro, it is necessary to establish fundamental correlations between bioreactor cultivating conditions, cell response, and the resulting structural and functional properties of the engineered tissue. Mathematical and computational modelling are indispensable tools in the analysis of such complex systems, generally applied to determine at least one of the following: (i) define in vitro cultivation conditions, (ii) characterize engineered tissues, and (iii) correlate cultivating conditions with the cell response and tissue properties (Obradovic et al., 2007).

In this work we focus on the tissue engineering of cartilage, which is of considerable clinical importance. Over the past decade significant progress has been made in the cultivation of cartilaginous equivalents as well as in mathematical modelling of cartilage tissue engineering systems. A detailed review of different mathematical and computational 
modelling strategies has recently been carried out (Sengers et al., 2007a,b). We highlight some of the contributions that are most relevant to the present work.

A deterministic continuum model of the progression of chondrogenesis within cell-polymer constructs during cultivation was developed starting from first principles by (Obradovic et al., 2000). In that model glycosaminoglycan (GAG) was chosen as a chondrogenesis marker since it is the major cartilage component together with collagen type II. The model accounted for consumption of oxygen, GAG synthesis as a function of the local oxygen concentration, and diffusion of both species, and was employed to calculate temporal and spatial patterns of GAG deposition. The predicted profiles of GAG concentration in engineered cartilage were quantitatively consistent with those measured via high-resolution $(40 \mu \mathrm{m})$ image processing of tissue samples (Martin et al., 1999). However, the model did not predict cell distributions nor the tissue growth and these parameters were determined experimentally and inserted as such in the model.

Cell distribution over time in engineered cartilage was modelled based on population balances by (Pisu et al., 2004, 2006) but the authors did not take into account that the cells are anchored to ECM and move together with it. Cell migration, proliferation, differentiation and programmed death in porous scaffolds were successfully modelled using a multiphase approach (Lemon and King, 2007). This model is very useful for systems with motile cells, but cannot be directly applied to systems with anchorage-dependent and stationary cells. However, the model is solved in a moving formulation including coordinate transformation, which provides an elegant account of growth at a moving boundary. Viscoelastic models have also been used to describe mechanical interaction between motile cells and their extracellular environment, assuming that all components - cells, scaffold, ECM - comprise a single phase moving at the same velocity. 
In vitro cartilage tissue growth in rotating bioreactors has been addressed using a model based on the volume-of-fraction method predicting stimulation of ECM deposition on surfaces exposed to higher hydrodynamic shear stresses (Lappa, 2003). In addition, one of the recent models (Bilgen et al., 2009) also addressed stimulatory effects of the bioreactor hydrodynamic environment on growth and properties of engineered cartilage.

It can be seen that many relevant aspects have been tackled in considerable detail, but this brief review highlights the need, ultimately, for an integrated model of tissue development to assist process optimisation. This would need the ability to predict from first principles, the phenomena of diffusion and consumption of nutrients, GAG synthesis and deposition, cell distributions and tissue growth and be capable of including experimental data from a prototype process. This paper reports a phenomenological model of cartilage tissue culture in a rotating bioreactor and its calibration and validation by comparisons with observations of (i) GAG synthesis, aggregation and leakage, (ii) spatial-temporal distributions of GAG and cells, and (iii) tissue growth (i.e. construct enlargement) reported previously in (Vunjak-Novakovic et al., 1999) and (Obradovic et al., 2000).

\section{BRIEF DESCRIPTION OF THE EXPERIMENT}

As a model system, we have chosen cartilage tissue engineering in rotating bioreactors, which were shown to promote in vitro chondrogenesis by dynamic laminar flow and efficient mass transport to the cultivated tissue (Vunjak-Novakovic et al., 1999, 2002). The experiment has been described in detail previously (Obradovic et al., 2000). Here we summarize the main points that are important for our model. Initially, 5 million articular bovine calf chondrocytes were dynamically uniformly seeded onto biodegradable polyglycolic acid (PGA) scaffolds (5 $\mathrm{mm}$ in diameter, $2 \mathrm{~mm}$ thick) for 3 days in mixed flasks. After this initial period the cellpolymer constructs were transferred into rotating bioreactors and cultivated for 6 weeks in 
total. In this experimental set-up it was shown that during the first four days the cells proliferate intensively, reaching approximately 11 million cells per scaffold. After this period, the cell number remains almost constant and the cell proliferation is negligible. It should be noted that chondrocytes are anchorage-dependent cells and shortly after seeding, surround themselves with ECM. For the first 10 days there is no growth of the constructs and matrix is deposited mainly in the outer zones of the scaffold indicating mass transfer limitations. Under the usual cultivation conditions, in a humidified incubator with $10 \% \mathrm{CO}_{2}$, the oxygen concentration in the medium during culture is about $80 \mathrm{mmHg}$. After an initial 10-12 days, the cell-polymer constructs start to increase in size depositing ECM on the periphery and filling the inner construct spaces so that tissue generation proceeds from the construct periphery both outward and toward the construct centre (Freed et al., 1998). During this process, ECM accumulation (i.e. the increase of GAG concentration) causes local expansion of construct elements. Thus, in a small region of tissue, the cell density changes because even though the number of cells is constant the volume of the region increases with expansion. Over 6 weeks in culture, cell density decreases and becomes almost uniform throughout the engineered tissue (Obradovic et al., 2000).

\section{MATHEMATICAL MODEL}

In the rotating bioreactor, engineered constructs are relatively unconstrained to grow in any direction, experiencing only hydrodynamic shear stresses and low mechanical forces during tumbling and sliding about a stationary point within the bioreactor. However, our attempts to apply stress-strain models previously used for wound healing (Murray and Oster, 1984; Murray, 2003) and for compaction of cell populated gels (Moon and Tranquillo, 1993) were unsuccessful due to lack of knowledge of constitutive equations and material properties of the constructs. Thus, in this study we have focused on understanding the main mechanisms 
responsible for the spatial distributions of nutrients, GAG and cells as well as for the construct growth.

In order to simplify the problem and test implementation of various modeling assumptions for different processes involved in tissue accumulation and growth, we trace the time evolution of distributions of oxygen, GAG and cells in one space-dimension by approximating the construct as a rectangular cross-section of a cylinder (Figure 2). In this way, we can predict spatial distributions of key variables without the need for the extensive use of numerical techniques or computational resources necessary in multi-dimensional simulations. We assume symmetry and model component distributions over the half-height $W / 2$ of the construct, which varies in time as a consequence of construct enlargement.

\section{Oxygen transport and consumption}

In this study we consider experimental conditions with an adequate supply of nutrients and a limiting role of oxygen. The local consumption rate is assumed to follow Michaelis-Menten kinetics, as used previously (Obradovic et al., 2000) leading to the differential equation predicting spatial and temporal changes in oxygen concentration $(\mathrm{O})$ within the construct:

$$
\frac{d O}{d t}=D_{o} \frac{\partial^{2} O}{\partial x^{2}}-L_{1} \frac{O C}{B_{0}+O}
$$

where $D_{o}$ is the effective oxygen diffusivity, $L_{1}$ is the maximal O-consumption rate, $\mathrm{C}$ is the cell concentration, and $B_{0}$ is the value of $\mathrm{O}$ at half-maximal $\mathrm{O}$-consumption rate. Thus, it is assumed that the cellular O-consumption is insensitive to the rate of GAG synthesis and that the effective oxygen diffusion coefficient does not depend on the GAG concentration.

\section{GAG synthesis, deposition and transport}


In several previous models of tissue growth, ECM has generally been regarded as a single material (Obradovic et al., 2000; Wilson et al., 2002; Pisu et al., 2004). In the present model we have adopted a more realistic approach (Klein and Sah, 2007) of a two-stage process of GAG accumulation: synthesis followed by aggregation. GAG degradation, considered as a separate process by (Klein and Sah, 2007) is taken into account here within the production term as product inhibition. Thus, when the maximum GAG concentration $G_{\max }$ is reached, corresponding to the physiological GAG concentration, it is held constant by continuous metabolism of the cells.

Newly synthesized and secreted proteoglycan monomers are free to diffuse in the cell surrounding and through the scaffold. In this model these monomers are referred to "unbound GAG”. Hyaluronate and link proteins are also synthesized and secreted independently from the cells. These three major components then form proteoglycan aggregates in the ECM. Since proteoglycan aggregates are large, negatively charged molecules confined by collagen fibres, they are practically immovable and in this model are referred to "bound GAG".

Thus the model includes two separate equations tracing the temporal evolution of the spatial distributions of unbound and bound GAG. The concentration of unbound GAG $G_{U B}$ is governed by an equation in a form previously described (Obradovic et al., 2000):

$$
\frac{d G_{U B}}{d t}=D_{G A G} \frac{\partial^{2} G_{U B}}{\partial x^{2}}+k_{G A G} O C F_{G A G}(t, G)-c_{1} G_{U B}
$$

where $F_{G A G}(t, G)=\left(1+\operatorname{MAX}\left[0,\left(t-t_{0}^{*}\right) A_{n}\right]\right) \times M A X\left[0,1-G / G_{\max }\right]$.

The first term on the right hand side of the Eq. (2) represents the diffusive transport of the unbound GAG with diffusivity $D_{G A G}$. The second term describes the rate of production of unbound GAG, which is proportional to the local oxygen and cell concentrations. The factor $F_{G A G}(t, G)$, as previously described (Obradovic et al., 2000), accounts for the fact that the 
production is time-varying and product-inhibited. The experimentally observed time variation is captured by the factor $1+\operatorname{MAX}\left[0,\left(t-t_{0}^{*}\right) A_{n}\right]$, which describes a slow, constant GAG production rate between the $2^{\text {nd }}$ and $12^{\text {th }}$ days followed by a linear increase with time after $t_{0}^{*}$ $=12$ days. Product-inhibition of unbound GAG production is included by means of the factor $\operatorname{MAX}\left[0,\left(1-G / G_{\max }\right)\right]$ where $\mathrm{G}$ is the local concentration of bound GAG. If $G>G_{\max }$ the effective production of unbound GAG ceases and cells maintain the bound GAG concentration in the tissue at the level $G_{\max }$ by slow GAG turnover. The third term on the right hand side of the Eq. (2) represents the first-order kinetics of transformation of unbound to the bound GAG with the rate constant $c_{1}$.

The concentration G of bound GAG is described by the first order kinetics of unbound GAG aggregation as:

$$
\frac{d G}{d t}=c_{1} G_{U B}
$$

\section{Cell distribution}

After approximately 4 days of seeding and initial culture, cells in constructs reach their final numbers and cell proliferation ceases. Thus, after this period, the total number of cells in the construct is constant and hence the equation governing the distribution of cell density $C$ must be:

$$
\frac{d C}{d t}=0
$$

As mentioned before, temporal changes in local cell densities are determined by the local ECM accumulation. One of the consequences of this hypothesis is that the observed changes between initial and final spatial cell distributions must match the observed changes in the construct size. Preliminary calculations based on experimental results (Obradovic et al., 
2000) indeed showed this correspondence. Since cell distributions and tissue construct size were independently measured, this modelling approach is further strengthened.

\section{Construct growth}

Our model deals only with one of the aspects of tissue growth - construct enlargement as a consequence of GAG accumulation - and does not distinguish some other possible stimulatory effects (e.g. hydrodynamic conditions) for tissue deposition and growth on construct surfaces. We aimed to determine the local rates of construct deformation, assumed to be caused by the accumulation of deposited GAG. Initially, conversion of unbound to bound GAG will fill the spaces in an almost empty scaffold. However, as the bound GAG concentration increases, adjacent GAG chains will come into close proximity inducing mutual electrostatic repulsion due to the negative charge (Freed et al., 1998; Seog et al., 2005) causing the construct to expand. In this conceptual description of construct enlargement, regions of high initial cell concentrations will experience high local GAG synthesis rates and subsequent volume expansion. Regions with lower cell concentrations, on the other hand, will experience lower GAG deposition and stretching. Consequently the cell distribution will tend to become more uniform with increasing time, as was actually observed experimentally (Obradovic et al., 2000). The simplest way to include this relation between GAG deposition and construct enlargement is to assume that increments in local strain due to construct expansion are proportional to increments of deposited GAG, provided that the local GAG concentration exceeds a certain minimum value $G_{\min }$.

Expressed in terms of deformation we propose the following equation for expansion of tissue elements

$$
\gamma=\frac{d \ell}{\ell}=\frac{\ell_{1}-\ell}{\ell}=\left\{\begin{array}{cc}
0 & \text { if } G \leq G_{\min } \\
E d G & \text { if } G>G_{\min }
\end{array}\right.
$$


where $\gamma$ is the local deformation of a construct element with original and deformed sizes $\ell$ and $\ell_{1}$ respectively, $d G$ is the deposited amount of bound GAG in a short time interval dt and is calculated using the Eq. (3). The new bound GAG and cell concentrations after the deformation are described by:

$$
C_{\ell_{1}}=C_{\ell} /(1+\gamma), \quad G_{\ell_{1}}=G_{\ell} /(1+\gamma)
$$

In this way, the Eqs. (5) and (6) take into account increase of the construct size and changes of bound GAG and cell concentrations. It should also be noted that the total mass of the bound GAG and the total cell number in the stretched element are maintained constant during the stretch.

\section{Initial and boundary conditions}

During the seeding phase, cells are attaching to the scaffold, proliferating and starting to produce GAG. However, the exact mechanism of these processes is not known while cell distribution is significantly changing due to cell attachment and proliferation. Instead of guessing unknown cell number and distribution, we have simplified this seeding period by separating the phase of attachment and proliferation (1 day) during which the cells reach the number and density experimentally measured at day 4, and the GAG production phase, which starts at the end of day 1 . With such initial conditions, the model predicts $0.5 \%$ ww GAG on day 3, which is in agreement with the experimental value of $0.7 \%$ ww (Vunjak-Novakovic et al., 1999) and serves as additional validation of our model. Summarising, the model starts $(t=0)$ at the end of day 1, when the initial concentrations of bound and unbound GAG are zero throughout the construct, and cell distribution is equal to experimentally measured spatial distribution $f_{C}(x)$ of chondrocytes at day 4. Initially, a constant oxygen concentration within the constructs is assumed corresponding to that in the culture medium $N_{O}$. 
At subsequent times, symmetry at the construct centre is imposed by means of zero spatial gradient boundary conditions in all equations. At the construct surface, constant values of oxygen and GAG concentrations in the culture medium are assumed corresponding to those experimentally determined, i.e. $N_{O}$ and 0 , respectively. In Table I, a summary of initial and boundary conditions is given.

\section{NUMERICAL SOLUTION PROCESS}

A two-stage process is used to evaluate changes in the construct over time. The initial construct half-height $W / 2$ is subdivided into $N_{\mathrm{X}}$ elements of equal sizes and initial distributions of oxygen, unbound and bound GAG, and cells are assigned to each element. The time period from day 2 to 41 is subdivided into $N_{\mathrm{T}}$ equal time steps, each of duration $\Delta t$. Equations (1)-(4) along with the ancillary Eqs. (5-6) for tissue growth, are solved through time as follows:

- Stage 1: Diffusion Step. Using the size distribution of construct elements obtained at the end of the previous time step, Eqs. (1-4) are solved to yield new distributions of oxygen and unbound and bound GAG.

- Stage 2: Stretch Step. The concentrations of oxygen, unbound and bound GAG are kept fixed inside each construct element and Eq. (5) is solved to compute the growth of each construct element, these sizes are then updated; distributions of cells and bound GAG are adjusted (Eq. (6)) to take account of growth keeping the mass of bound GAG and the cell number constant within each element.

The Crank-Nicolson finite difference method (Chung, 2002) was used for Stage 1 to discretise Eqs. (1-3). The method applies local three-node parabolic interpolation functions to 
evaluate derivatives on the non-uniform grids that arise after tissue growth commences. The well-known public-domain solver Lapack (http://www.netlib.org/lapack/double/dgbsv.f) was used to solve the resulting banded system of linear equations.

At the start of Stage 2 the construct height will be subdivided into $N_{\mathrm{X}}$ elements with the size $\Delta x_{\mathrm{i}}$. According to Eq. (5) the length of the $\mathrm{i}^{\text {th }}$ element will experience the following increase provided that the local bound GAG concentration satisfies $G_{\mathrm{i}}>G_{\min }$ at the end of the Stage 1:

$$
\Delta x_{i, N E W}=\Delta x_{i}+\Delta x_{i} \times E \times \frac{d G_{i}}{d t} \times \Delta t
$$

where $\Delta x_{\mathrm{i}, \mathrm{NEW}}$ is the new element size at the end of the time step $\Delta t$ and $\mathrm{E}$ is the expansion coefficient.

According to Eq. (6) the concentrations of bound GAG and cells are updated according to the following rules:

$$
\begin{aligned}
& G_{i, N E W}=G_{i}\left(\Delta x_{i} / \Delta x_{i, N E W}\right) \\
& C_{i, N E W}=C_{i}\left(\Delta x_{i} / \Delta x_{i, N E W}\right)
\end{aligned}
$$

It should be noted that more accurate multi-step integration schemes could be applied, but the above numerical procedure is sufficiently accurate to demonstrate our conceptual model.

Dependence of the results on the initial mesh spacing $\Delta x=W / 2 \times 1 / N_{X}$ and the time step size $\Delta t$ was investigated by systematic variation of these parameters and inspecting variations in the unbound GAG leakage from the construct. The results were found to be mesh-independent around $N_{\mathrm{X}}=1,000$ and $N_{\mathrm{T}}=10,000$, corresponding to $\Delta x=1 \mu \mathrm{m}$ and $\Delta t=$ $346 s$. 


\section{PARAMETER ESTIMATION}

The system parameters were estimated from literature sources (Table II), but the experimental uncertainty of the values is rarely documented and may depend on process conditions in ways that are not accurately known. Values of four of these parameters, as well as two new parameters introduced in the present model, were obtained by fitting the numerical results to the experimental data.

It should be noted here that experimental data on cell and GAG distributions measured in 2D histological cross-sections had to be normalized in the present model to $1 \mathrm{D}$ coordinates taking into account the constant total number of cells over the cultivation time. Thus, the experimental cell distribution on day 41 had to be multiplied by the ratio of the initial and final construct cross-sectional areas $\left(\left(d_{\text {final }} / d_{\text {start }}\right)^{2}=1.62\right)$, where $\mathrm{d}_{\text {start }}=5.5 \mathrm{~mm}$ and $\mathrm{d}_{\text {final }}=7$ mm, as determined experimentally (Obradovic et al., 2000).

\section{- Oxygen diffusivity $D_{O}$}

In the present model, the oxygen diffusion coefficient in the growing constructs was assumed to be $D_{O}=2.4 \times 10^{-3} \mathrm{~mm}^{2} / \mathrm{s}$ corresponding to $80 \%$ of that reported for water. This is in agreement with the composition of native bovine calf cartilage, reported to contain about $80 \%$ of water, as well as with the composition of engineered cartilage constructs cultivated in rotating bioreactors for 6 weeks that contained about $90 \%$ of water (Vunjak-Novakovic et al., 1999).

\section{- Maximum bound GAG concentration $G_{\max }$}

The maximum GAG concentration in constructs was assumed to be approximately $G_{m a x}=5.3$ $\%$ ww, which is in the range of values reported for bovine calf cartilage (Table II) and in agreement with the value (5.5\%ww) used in the previous model (Obradovic et al., 2000). 


\section{Unbound $G A G$ diffusivity $D_{G A G}$}

Diffusivity of unbound GAG, $D_{\mathrm{GAG}}$, was reported to lie in the range $10^{-7}-10^{-6} \mathrm{~mm}^{2} / \mathrm{s}$ (Klein and Sah, 2007). In this work, we have assumed a value of $10^{-7} \mathrm{~mm}^{2} / \mathrm{s}$ and verified it by comparisons of the model predictions with experimentally measured rates of GAG leakage from the constructs, reported to be $1.90 \times 10^{-6} \mathrm{~g} / 1$ yielding approximately $30 \%$ GAG leakage of total GAG produced (Obradovic et al., 2000).

\section{Unbound GAG production rate constant $k_{G A G}$}

The unbound GAG production rate constant $k_{G A G}$ was estimated from the best-fit of experimentally determined GAG profiles at day 10 . This time is just prior to the onset of construct growth, which reduces the number of different mechanisms that influence GAG distribution. The minimum standard deviation between the model predictions and experimental data at $t_{0}=10$ days is found when $k_{\mathrm{GAG}}=2.38 \% \mathrm{ww} /\left(\right.$ day.mM. $\left.10^{5} \mathrm{cell} / \mathrm{mm}^{3}\right)$ i.e. close to the value determined in (Obradovic et al., 2000).

\section{Construct growth parameters $G_{\min }$ and $E$}

The maximum of experimentally measured GAG concentration in constructs on day 10 is around $4 \%$ ww. So, we expect that the value of $G_{m i n}$, which determines the onset of the construct growth in Eq. (5) will be close to this value. The optimal values of $G_{\min }$ and the expansion coefficient $E$ must match the observed $1 \mathrm{~mm}$ increase of the construct height on day 41 and minimises discrepancies between the observed and predicted GAG distributions. The details are beyond the scope of this paper, but it should be noted that the final values of $G_{\min }$ and $E$ will depend on the exact target distributions chosen for optimisation. The values $G_{\min }=4.1 \% \mathrm{ww}$ and $E=17.17$ were used in this paper model since it allowed predicted 
construct height to match the measured value on day 41 and had low STD with the best qualitative agreement.

To conclude this section we summarise the revised and additional estimates of system parameters in Table III and the targets used for their optimisation.

\section{RESULTS \& DISCUSSION}

Figure 3 shows the predicted spatial distributions of oxygen, cells, unbound and bound GAG for a selection of time points between the beginning and end of the experiment. The horizontal axis, coordinate $\mathrm{x}$, indicates the distance along the construct height where the increase in the base width of the distributions indicates the enlargement of the construct. The predicted spatial distributions of oxygen decreases with depth due to uptake by the cells (Figure 3a), which is typical of a steady-state diffusion problem with a distributed sink. Decrease of oxygen concentration along the centreline with time is caused by the increase in construct size, increasing the distance for diffusion from the edge to the centreline. The construct growth results in a general decrease of the cell concentration (Figure $3 b$ ) since the number of cells remains constant over the cultivation time. Cell density predicted by our model remains higher at construct surfaces than in the interior over the whole cultivation time. This is informed by our model's prediction that, in spite of the initial high cell number in the external construct region, this region will not undergo significant volume expansion. This is, in turn, based on our observations which confirm that, whilst cells in the external construct region produce GAG, it leaks out of the construct without the opportunity to convert to bound GAG, and consequently the tissue elements are not stretched and cell density is not decreased. Distributions of unbound and bound GAG are consistent with these trends (Figures 3c,d). On day 4 large peaks are predicted in distributions of both species near the construct edge where the initial cell density is the highest. In this region the bound GAG concentration 
will first reach the threshold value $G_{\min }$ in Eq. (5), determining the onset of local tissue expansion due to GAG deposition.

The temporal behaviour of the unbound GAG concentration is predicted to peak early (around day 4). Between days 1 and 10 the bound GAG concentration also rapidly rises to about half its maximum value $G_{\max }$. Both distributions follow the general pattern of the cell density distribution at this stage suggesting a period of fairly unconstrained GAG production. After day 10 the product-inhibition effect built into the factor $F_{\mathrm{GAG}}$ in Eq. (2) starts to dominate the unbound GAG production term. The unbound GAG concentration gradually decreases to about $15 \%$ of its peak value on day 41 . As this process unfolds, the unbound GAG distribution becomes more uniform due to the combined effects of product-inhibition and diffusion. Without a diffusion or a sink term, the bound GAG distribution is dominated by local accumulation in response to the production due to the binding source term, so it continually increases. Construct growth provides a redistributing effect, which tends to smooth out the bound GAG distribution. Figure $3 \mathrm{~d}$ clearly shows that the coupling between the unbound and bound GAG equations correctly regulates the bound GAG concentration towards a maximum of around 5.3\%ww towards the end of the experiment. Between 30 and 41 days the interplay between product-inhibition and rapid changes in O-concentration, cell density and bound GAG concentration causes a complex distribution of unbound GAG with sharp peaks near the construct edge (Figure 3c).

The unbound GAG concentration was observed to have the most complex dynamical behaviour. Figure 4 compares the size of the space integrated values of the various terms in Eq. (2) to explore this in more detail. Except for a period of a few days after the start of the experiment, the space integrated unbound GAG concentration is dominated by the balance between the production and consumption terms. The imbalance between these two terms 
generates some local accumulation immediately after the experiment has started, but most of the time diffusive transport will remove any excess production.

Figure 5 shows spatial distributions of the ratio of diffusion and production term on selected days between 4 and 41 , as well as the distributions of local production and diffusion. These diagrams confirm that both the diffusion and production terms exhibit strong peaks near the construct edge. The small positive peak in the diffusion-production ratio represents a quotient of small numbers, whereas the peak value of -1 at the outer edge shows that all unbound GAG that is locally produced is lost to leakage by diffusion. Elsewhere the diagrams indicate that the unbound GAG is converted to bound GAG. Without a sufficient increase in the bound GAG concentration, the construct does not expand locally and the high initial cell density is maintained in this progressively narrower edge region as highlighted in the discussion of Figure 3(b).

The model predicts an almost linear increase in the height of the construct and fits the available experimental data measured on days 10 and 41 (Figure 6). A constant average construct growth rate between days 10 and 41 was assumed in previous mathematical models of cartilage tissue engineering in rotating bioreactors (Obradovic et al., 2000; Lappa 2003), which successfully predicted changes in morphological appearance of the constructs over time (Lappa, 2003). The construct growth predicted by our model is in agreement with this assumption but still needs to be experimentally verified.

Validation of the mathematical model is accomplished by comparison of the predicted distributions of cell densities on days 10 and 41 , as well as of bound GAG on the $41^{\text {st }}$ day of cultivation, with the experimental data (Figure 7). The numerical results successfully predict the very sharp peak in the cell distribution near the construct edge and almost uniform cell density throughout the construct, confirming that the model captures the main features of construct growth with good accuracy. Model predictions and measured values of the bound 
GAG concentration with experimental standard deviations from (Obradovic et al., 2000) are shown in Figure 7(b). The distribution on day 10 is predicted within the experimental uncertainty, as expected, since this distribution was used to calibrate construct growth parameters $G_{\min }$ and $E$. On day 41 the bound GAG concentration near the centre of the construct is accurately predicted, but there are significant discrepancies between experimental and numerical results in the outer zone of the construct. The mathematical model appears to be lacking a mechanism to decrease the bound GAG concentration in this region. The inevitable appearance of a fluid boundary layer exterior to the construct suggests that the cause may be hydrodynamic in nature. There are several ways in which fluid flow might exert influence over the processes governing unbound GAG. These include hydrodynamic shear, which can cause cell dedifferentiation (Vunjak-Novakovic et al., 1996) and affect tissue growth (Lappa, 2003). Also the precise values of $G_{\min }$ and $\mathrm{E}$ are unknown and may vary throughout the construct and over time. There may also be an unknown mechanism of tissue growth on the construct surface such as the direct effect of hydrodynamic stimulation, as suggested by (Lappa, 2003). It may be possible to include an adjustment to overcome this limitation. However, since the exact biological or hydrodynamical cause is unknown, this would have to be a purely empirical correction based on the results of an experiment. Since we are interested in the underlying mechanisms, we leave this as an item for future experimental and theoretical investigation.

The general agreement between experimental data and numerical predictions suggests that our model successfully incorporates most of the biological processes that are currently known to affect regeneration of engineered cartilage tissue. However, the description of these processes has been greatly simplified. Subject to availability of values of relevant system parameters it would be fairly straightforward to expand the model to include a more sophisticated account of the nutrient environment, including separate transport equations for 
additional nutrient species. The production and outward diffusion of metabolic waste products can be described by further species equations making it possible to resolve environmental conditions such as $\mathrm{pH}$. Moreover, the model could be expanded to account for production and accumulation of cell secreted stimulating growth factors, but additional experimental data is needed to determine the exact roles of these factors and influences on GAG production rates over the cultivation time.

In addition, the model could be further developed to incorporate collagen synthesis and accumulation when appropriate experimental data becomes available. With collagen incorporation, GAG - collagen interactions can be defined and used to describe unbound to bound GAG turnover in a more realistic manner. Also incorporation of collagen will limit stretching of the tissue elements and consequent construct growth.

It is also possible that our model could be linked to models predicting biomechanical properties of cartilaginous tissues (e.g. Vunjak-Novakovic et al., 1999, Williamson et al., 2001; Hasler et al., 1999) and used to distinguish the effects of bound and unbound GAG.

For example, it would be interesting to apply the model to cartilage tissue engineering systems employing physical stimulation (Hu and Athanasiou, 2006; Mauck et al., 2000) if the data on local GAG concentrations and GAG release are available. However, special attention is needed to account for mechanical stimulation, which according to (Mauck et al., 2003) could cause changes in the rate of unbound GAG production as well as in the transport rates of GAG, nutrients and metabolic products.

It should also be noted that the values of system parameters should be more accurately determined. The numerical results were found to be quite sensitive to oxygen and unbound GAG diffusivity. Moreover, the dependence of these diffusivities on local conditions was recognised, but not explicitly included in the present model. Further experimental work to quantify these parameters as well as unbound GAG production rate and unbound-bound GAG 
binding rate more accurately would clearly be beneficial. In the meantime, the effect of lack of knowledge on the model outcomes can be explored by means of the type of sensitivity analysis that was used for the estimation of uncertain system parameters.

In spite of the reservations noted above, our mathematical model has successfully integrated all known biological and transport mechanisms processes that govern regeneration of engineered cartilage tissue in a rotating bioreactor with a simple, but effective, account of the interplay between GAG production and deposition, cell density distribution and construct enlargement. It is the first model proposed to include mechanisms of GAG accumulation and tissue enlargement offering an approach attractive to be extended to other tissues and tissue engineering systems.

\section{CONCLUDING REMARKS}

We have proposed a conceptually simple phenomenological model of GAG deposition and growth of an engineered tissue construct cultured in a rotating bioreactor. Models of tissue growth generally regard the extracellular matrix as a single substance. Our model recognises that proteoglycans are initially produced by cells in a mobile form, which we have termed "unbound GAG", part of which is slowly converted within the ECM into immobile aggregates termed "bound GAG". This more realistic account of the production process has allowed us to account for the experimentally-observed substantial rates of leakage of GAG from the edge of tissue construct. Furthermore, the model recognises the anchorage-dependent nature of chondrocytes in cartilaginous tissues. During the main cultivation phase and ECM regeneration, the total number of cells in the construct is constant, but their local distribution is controlled by local stretching of tissue elements, which in turn is governed by local rates of GAG deposition. The model lends itself well as a test bed for different growth rules. The agreement between the predicted trends of cell distribution and construct enlargement with 
measurements confirms the validity of this simple connection between GAG deposition, cell distribution and tissue deformation in cases without significant mechanical stimulation of tissue growth.

We must acknowledge a remaining weakness of our model, which is the relatively poor agreement of predicted and measured profiles of GAG concentration in the surface layer of $\sim 200 \mu \mathrm{m}$ of the construct. It is likely that this is attributable to (i) the effects of hydrodynamic shear at tissue surfaces, which can affect cell dedifferentiation (VunjakNovakovic et al., 1996) and tissue growth (Lappa, 2003), (ii) unknown value of $G_{\min }$ and exact value of repulsion $\mathrm{E}$, which may differ throughout the construct and over time, and/or (iii) possibly other mechanisms of tissue growth on the surface such as direct effect of hydrodynamic stimulation, as suggested by (Lappa, 2003). These effects clearly require future study.

Nevertheless, our model has captured the major phenomena and kinetics controlling the spatial and temporal characteristics of cartilage tissue in a rotating bioreactor. It can be readily extended $2 \mathrm{D}$ or $3 \mathrm{D}$ and the validation of its predictive capability - against a selection of measured data that were not used to construct the model - suggests that it may be a useful starting point for the development of procedures for the optimisation of tissue growth environment.

\section{Acknowledgements}

This work forms part of the UK EPSRC funded Innovative Manufacturing Grand Challenge in Regenerative Medicine - Remedi. Remedi is a partnership of Loughborough, Nottingham, Cambridge, Birmingham, Ulster and Liverpool Universities, together with Industry and Agency stakeholders. B. Obradovic is grateful to the Ministry of Science of the Republic of Serbia (grant 142075) for supporting her research. H.K.Versteeg acknowledges useful 
discussions with delegates at the $8^{\text {th }}$ Mathematics in Medicine Study Group sponsored by EPSRC and held at Loughborough University on 15-19 September 2008. 


\section{REFERENCES}

Bilgen B, Uygun K, Bueno EM, Sucosky P, Barabino GA. 2009. Tissue Growth Modeling in a Wavy-Walled Bioreactor. Tissue Eng. A. 15 (4): 761-771.

Chung TJ. 2002. Computational Fluid Dynamics. Cambridge: Cambridge University Press.

Freed LE, Hollander AP, Martin I, Barry JR, Langer R, Vunjak-Novakovic G. 1998.

Chondrogenesis in a cell-polymer-bioreactor system. Experimental Cell Research 240(1):58-65.

Freshney RI, Obradovic B, Grayson WL, Cannizzaro C, Vunjak-Novakovic G. 2007. Principles of Tissue Culture and Bioreactor Design. In: Lanza RP, Langer R, Vacanti J, editors. Principles of Tissue Engineering: Academic Press. p 155 - 181.

Haselgrove JC, Shapiro IM, Silverton SF. 1993. Computer Modeling of the Oxygen Supply and Demand of Cells of the Avian Growth Cartilage. American Journal of Physiology 265(2):C497-C506.

Hasler EM, Herzog W, Wu JZ, Müller W, Wyss U. 1999. Articular cartilage biomechanics: theoretical models, material properties, and biosynthetic response. Crit. Rev. Biomed. Eng. 27(6):415-488.

Himmelblau DM. 1964. Diffusion of Dissolved Gases in Liquids. Chem. Rev. 64(5):527 550.

Hu JC, Athanasiou KA. 2006. The Effects of Intermittent Hydrostatic Pressure on SelfAssembled Articular Cartilage Constructs. Tissue Engineering 12(5): 1337-1344.

Klein TJ, Sah RL. 2007. Modulation of depth-dependent properties in tissue-engineered cartilage with a semi-permeable membrane and perfusion: a continuum model of matrix metabolism and transport. Biomechanics and Modeling in Mechanobiology 6(1-2):21-32. 
Lappa M. 2003. Organic tissues in rotating bioreactors: Fluid-mechanical aspects, dynamic growth models, and morphological evolution. Biotechnology and Bioengineering 84(5):518-532.

Lemon G, King JR. 2007. Multiphase modelling of cell behaviour on artificial scaffolds: effects of nutrient depletion and spatially nonuniform porosity. Mathematical Medicine and Biology-a Journal of the IMA 24(1):57-83.

Mauck RL, Hung CT, Ateshian GA. 2003. Modeling of neutral solute transport in a dynamically loaded porous permeable gel: implications for articular cartilage biosynthesis and tissue engineering. J. Biomech. Eng. 125(3):602-614.

Mauck RL, Soltz MA, Wang CC, Wong DD, Chao PH, Valhmu WB, Hung CT, Ateshian GA. 2000. Functional Tissue Engineering of Articular Cartilage Through Dynamic Loading of Chondrocyte-Seeded Agarose Gels. J. Biomech. Eng. 122(3): 252-260.

Martin I, Obradovic B, Freed LE, Vunjak-Novakovic G. 1999. Method for quantitative analysis of glycosaminoglycan distribution in cultured natural and engineered cartilage. Annals of Biomedical Engineering 27(5):656-662.

Moon AG, Tranquillo RT. 1993. Fibroblast-populated collagen microsphere assay of cell traction force: Part 1. Continuum model. AIChe Journal 39(1):163-177.

Murray JD. 2003. Dermal Wound Healing. Mathematical Biology II Spatial Models and Biomedical Applications: Springer Verlag.

Murray JD, Oster GF. 1984. Cell traction models for generating pattern and form in morphogenesis. Journal of Mathematical Biology 19(3):265-279.

Obradovic B, Carrier RL, Vunjak-Novakovic G, Freed L.E. 1999. Gas exchange is essential for bioreactor cultivation of tissue engineered cartilage. Biotechnol. Bioeng. 63: 197205. 
Obradovic B, Meldon JH, Freed LE, Vunjak-Novakovic G. 2000. Glycosaminoglycan deposition in engineered cartilage: Experiments and mathematical model. AIChe Journal 46(9):1860-1871.

Obradovic B, Radisic M, Vunjak-Novakovic G. 2007. Oxygen Transport in Tissue Engineering Systems: Cartilage and Myocardium. FDMP 3(3):189-202.

Pisu M, Lai N, Cincotti A, Concas A, Cao GC. 2004. Modeling of engineered cartilage growth in rotating bioreactors. Chemical Engineering Science 59(22-23):5035-5040.

Pisu M, Lai N, Concas A, Cao G. 2006. A novel simulation model for engineered cartilage growth in static systems. Tissue Engineering 12(8):2311-2320.

Sengers BG, Please CP, Oreffo ROC. 2007a. Experimental characterization and computational modelling of two-dimensional cell spreading for skeletal regeneration. Journal of the Royal Society Interface 4:1107-1117.

Sengers BG, Taylor M, Please CP, Oreffo ROC. 2007b. Computational modelling of cell spreading and tissue regeneration in porous scaffolds. Biomaterials 28(10):1926-1940.

Seog J, Dean D, Rolauffs B, Wu T, Genzer J, Plaas AHK, Grodzinsky AJ, Ortiz C. 2005. Nanomechanics of opposing glycosaminoglycan macromolecules. Journal of Biomechanics 38(9):1789-1797.

Vunjak-Novakovic G, Freed LE, Biron RJ, Langer R. 1996. Effects of Mixing on the Composition and Morphology of Tissue-Engineered Cartilage. AIChE Journal 42(3):850-860.

Vunjak-Novakovic G, Goldstein SA. 2005. Biomechanical principles of cartilage and bone tissue engineering. In: Mow V, C., Huiskes R, editors. Basic Orthopaedic Biomechanics and Mechanobiology. p 343-408.

Vunjak-Novakovic G, Martin I, Obradovic B, Treppo S, Grodzinsky AJ, Langer R, Freed LE. 1999. Bioreactor cultivation conditions modulate the composition and mechanical 
properties of tissue-engineered cartilage. Journal of Orthopaedic Research 17(1):130138.

Vunjak-Novakovic G, Obradovic B, Martin I, Bursac PM, Langer R, Freed LE. 1998. Dynamic cell seeding of polymer scaffolds for cartilage tissue engineering. Biotechnology Progress 14(2):193-202.

Vunjak-Novakovic G, Obradovic B, Martin I, Freed LE. 2002. Bioreactor studies of native and tissue engineered cartilage. Biorheology 39(1-2):259-268.

Wilson CG, Bonassar LJ, Kohles SS. 2002. Modeling the dynamic composition of engineered cartilage. Archives of Biochemistry and Biophysics 408(2):246-254.

Williamson AK, Chen AC, Sah RL. 2001. Compressive properties and function-composition relationships of developing bovine articular cartilage. J. Orthop. Res. 19(6) : 11131121. 
Table I: Summary of initial conditions and boundary conditions

\begin{tabular}{|c|c|l|l|l|}
\hline Equation. & Variable & Initial condition & \multicolumn{2}{|c|}{ Boundary conditions } \\
& & & at $t=0\left(1^{\text {st }}\right.$ day $)$ & \multicolumn{2}{|c|}{} & construct edge $(x=\mathrm{W} / 2)$ \\
\cline { 3 - 5 } & & & & \\
\hline$(1)$ & $\mathrm{O}$ & $O(x, t=0)=N_{0}$ & $\partial O / \partial x=0$ & \\
\hline$(2)$ & $\mathrm{G}$ & $G_{U B}(x, t=0)=0$ & $\partial G_{U B} / \partial x=0$ & $G_{U B}=0$ \\
\hline$(3)$ & $\mathrm{G}$ & $G(x, t=0)=0$ & - & \\
\hline$(4)$ & $\mathrm{C}$ & $C(x, t=0)=f_{C}(x)$ & - & \\
\hline
\end{tabular}

Table II: System parameters 


\begin{tabular}{|c|c|c|c|}
\hline Symbol & Parameter & Value & Source \\
\hline$L$ & $\begin{array}{l}\text { half of the scaffold } \\
\text { thickness }\end{array}$ & $1 \mathrm{~mm}$ & (Obradovic et al., 2000) \\
\hline$d$ & scaffold diameter & $5 \mathrm{~mm}$ & (Obradovic et al., 2000) \\
\hline${ }^{\bullet} N_{C}$ & $\begin{array}{l}\text { number of cells in the } \\
\text { construct }\end{array}$ & $1.1 \times 10^{7}$ cells & (Obradovic et al., 2000) \\
\hline$N_{O}$ & $\begin{array}{l}\text { oxygen concentration in } \\
\text { the culture medium }\end{array}$ & $0.125 \mathrm{mM}$ & (Obradovic et al., 2000) \\
\hline${ }^{\dagger} D_{O}$ & oxygen diffusivity & $1.5 \times 10^{-3} \mathrm{~mm}^{2} \mathrm{~s}^{-1}$ & $\begin{array}{l}\text { (Obradovic et al., 2000; } \\
\text { Himmelblau, 1964) }\end{array}$ \\
\hline$L_{1}$ & $\begin{array}{l}\text { maximum oxygen } \\
\text { consumption rate }\end{array}$ & $1.86 \times 10^{-13} \mathrm{~mol} .\left(10^{5} \mathrm{cell}\right)^{-1} \cdot \mathrm{s}^{-1}$ & (Obradovic et al., 2000) \\
\hline$B_{O}$ & $\begin{array}{l}\text { oxygen concentration at } \\
\text { half-maximal } \\
\text { consumption rate }\end{array}$ & $6 \times 10^{-3} \mathrm{mM}$ & $\begin{array}{l}\text { (Obradovic et al., 2000) } \\
\text { (Haselgrove et al., } \\
\text { 1993) }\end{array}$ \\
\hline$D_{G A G}$ & unbound GAG diffusivity & Range $10^{-7}-10^{-6} \mathrm{~mm}^{2} \mathrm{~s}^{-1}$ & (Klein and Sah, 2007) \\
\hline${ }^{\dagger} k_{G A G}$ & $\begin{array}{l}\text { unbound GAG } \\
\text { production rate }\end{array}$ & $\begin{array}{l}2.3 \% \mathrm{ww} /(\text { day.mM. } \\
\left.10^{5} \mathrm{cell} / \mathrm{mm}^{3}\right)\end{array}$ & (Obradovic et al., 2000) \\
\hline$t_{0}$ & $\begin{array}{l}\text { start time of construct } \\
\text { growth }\end{array}$ & 10 day & (Obradovic et al., 2000) \\
\hline$t_{0}^{*}$ & $\begin{array}{l}\text { start time of accelerated } \\
\text { GAG production }\end{array}$ & 12 day & (Obradovic et al., 2000) \\
\hline$A_{n}$ & accelerated GAG & 0.11 day $^{-1}$ & (Obradovic et al., 2000) \\
\hline
\end{tabular}




\begin{tabular}{|l|l|l|l|}
\hline & production rate constant & & \\
\hline${ }^{\dagger} G_{\text {max }}$ & maximum bound GAG & Range 5.0-6.0 \%ww & (Obradovic et al., 2000) \\
& concentration & & \\
\hline$c_{1}$ & GAG binding rate & $1.2 \times 10^{-5} \mathrm{~s}^{-1}$ & (Klein and Sah, 2007) \\
\hline
\end{tabular}

- Experimental data in (Obradovic et al., 2000) showed $\pm 20 \%$ variations of the cell count on day 4, 10 and 41. These were attributed to the measurement technique and a constant cell count was assumed to obviate the need to include a population balance.

$\dagger$ Firm or revised estimate of the parameter is developed in section Parameter Estimation

TABLE III: Summary of revised and additional system parameter estimates 


\begin{tabular}{|l|l|l|l|}
\hline Symbol & Parameter & Value & Measured quantity used for \\
parameter selection
\end{tabular}


Figure captions:

Figure 1. Cartilage tissue engineering model system. a) Bovine articular cartilage, safranin O stain, x20 original magnification. Columnar arrangement of chondrocytes in lacunae surrounded by abundant ECM. b) Chondrocytes attached on PGA fibres after 3 days of seeding (SEM, scale bar: $10 \mu \mathrm{m})$ (with permission from (Vunjak-Novakovic et al., 1998)). c) Rotating bioreactor: cell-polymer constructs are suspended in medium flow, settling at a stationary point in tumble-slide regime. d, e, f) Progression of chondrogenesis in cell-polymer constructs cultivated in rotating bioreactors after: d) 5 days, e) 10 days, f) 41 days. Safranin O stain (adapted with permission from (Obradovic et al., 2000)).

Figure 2. Real 3D construct is approximated with a $1 \mathrm{D}$ rectangular cross-section of the cylinder. $\mathrm{W}=2 \mathrm{~mm}$ is the initial height of the cylinder, which after 41 days increases to $\mathrm{W}=3 \mathrm{~mm} ; \mathrm{x}$ axis represents the distance along the construct height, in-between $\mathrm{x}= \pm \mathrm{W} / 2$.

Figure 3. Predicted spatial distributions of (a) oxygen, (b) cells, (c) unbound GAG and (d) bound GAG at selected times between day 1 and 41. (Unbound and bound GAG distributions on day 1 are zero).

Figure 4. Temporal behaviour of space integrated values of terms in Eq. (2): $\int_{-W / 2}^{W / 2} \frac{d G_{U B}}{d t} d x-$ transient, $\int_{-W / 2}^{W / 2} D_{G A G} \frac{\partial^{2} G_{U B}}{\partial x^{2}} d x$ - diffusion, $\int_{-W / 2}^{W / 2} k_{G A G} O C F_{G A G} d x$-production and $\int_{-W / 2}^{W / 2} c_{1} G_{U B} d x-$ consumption.

Figure 5. Spatial distributions of (a) ratio of diffusion / production, (b) production and (c) diffusion of unbound GAG. 
Figure 6. Comparison of measured (exp.) and modelled (mod.) increase of the height of the construct.

Figure 7. Comparison of measured and predicted spatial distributions of (a) cells and (b) bound GAG on days 10 and 41. Experimental GAG concentration profiles (symbols) measured by image processing of construct sections (average $\pm \mathrm{SD}, n=2-4$ ) are taken from (Obradovic et al., 2000). 
a)

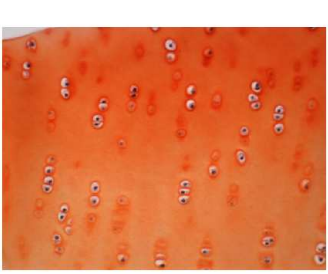

d)

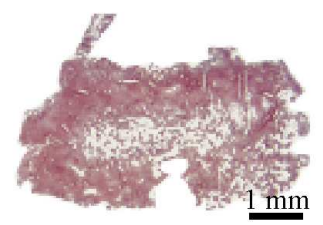

b)

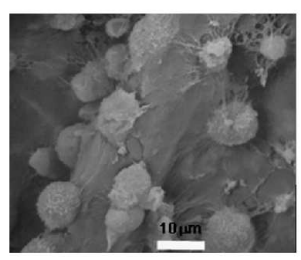

e)

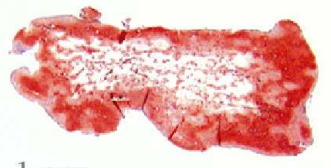

$\underline{1 \mathrm{~mm}}$ c)
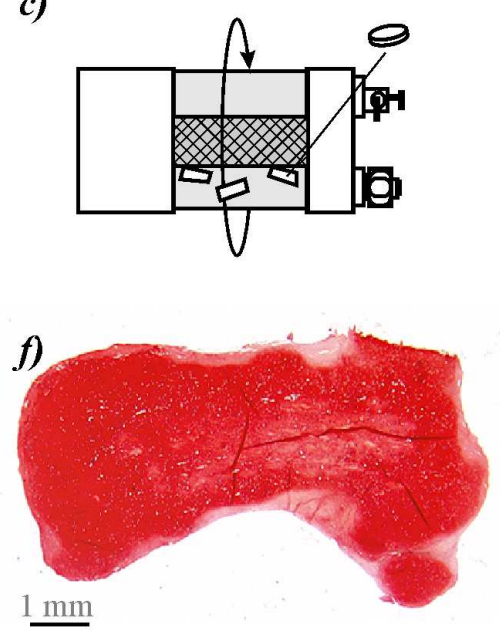

Figure. 1 


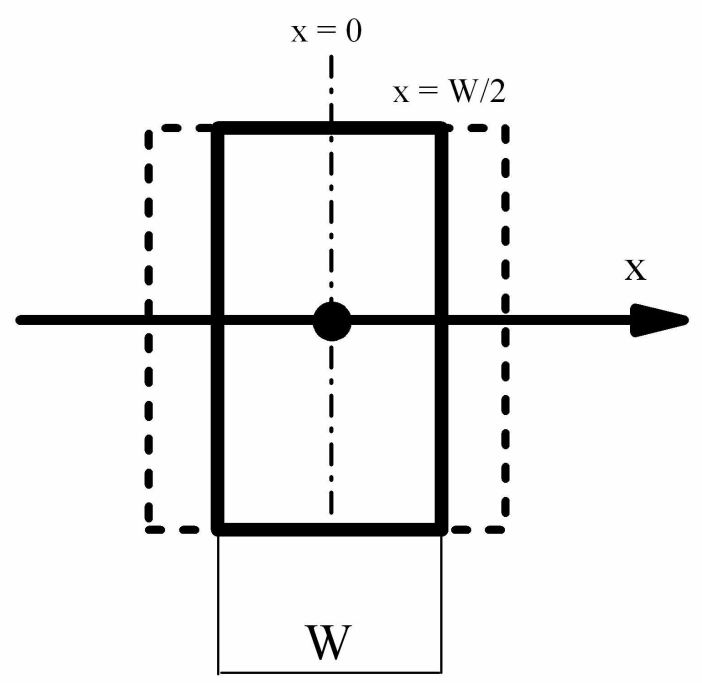

Figure. 2

$241 \times 222 \mathrm{~mm}(300 \times 300$ DPI $)$

John Wiley \& Sons 

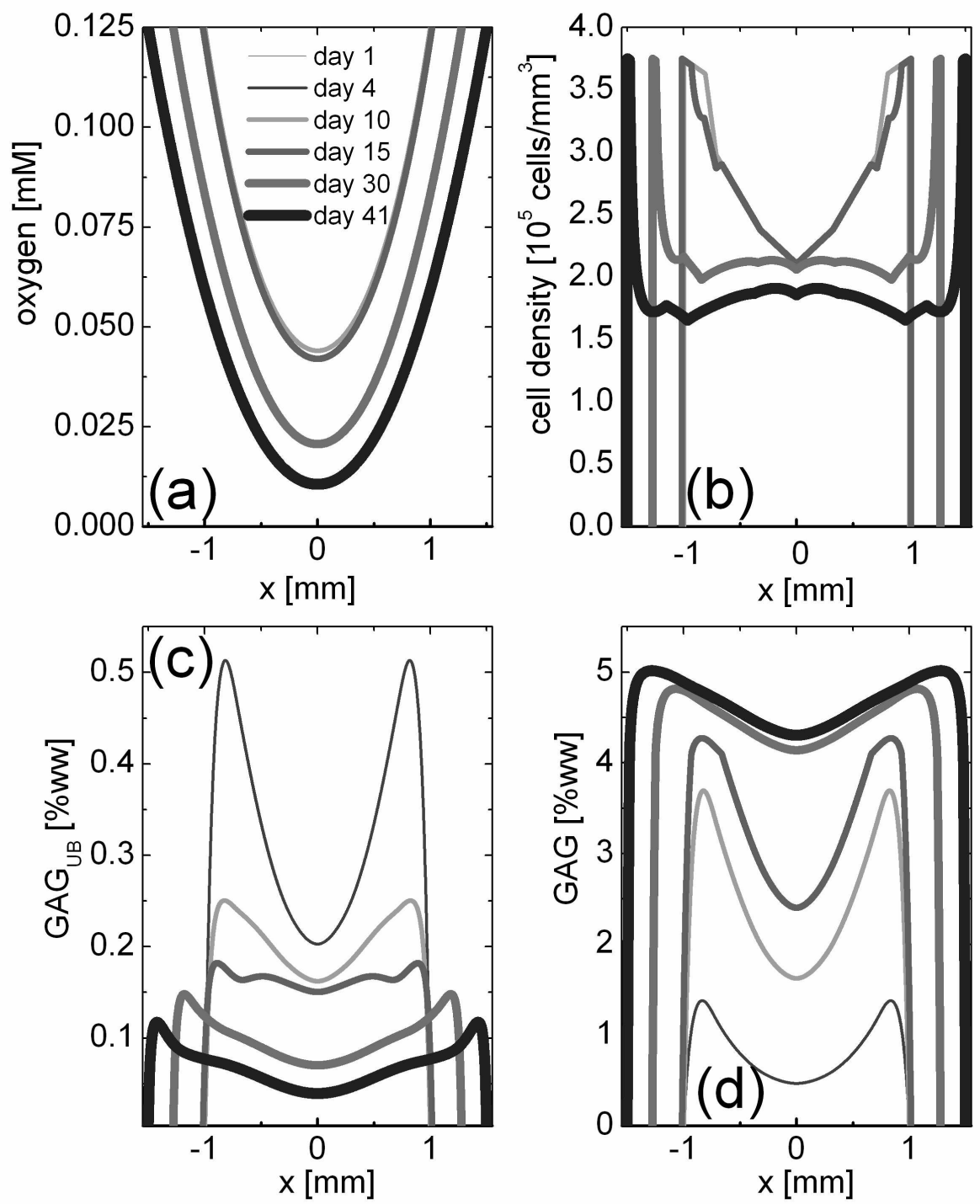

Figure. 3

$219 \times 261 \mathrm{~mm}(300 \times 300$ DPI $)$ 


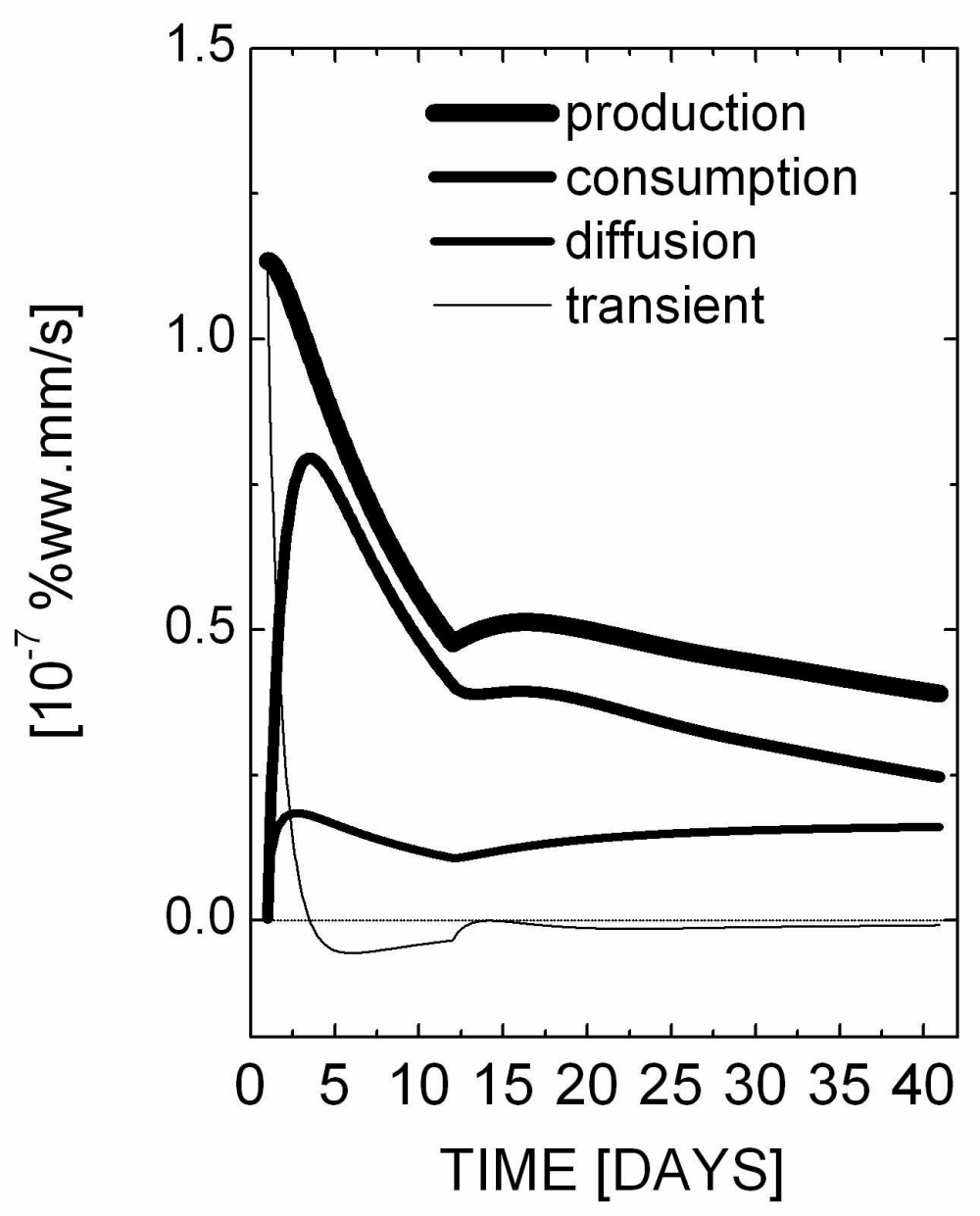

Figure. 4

$142 \times 165 \mathrm{~mm}(300 \times 300$ DPI $)$ 

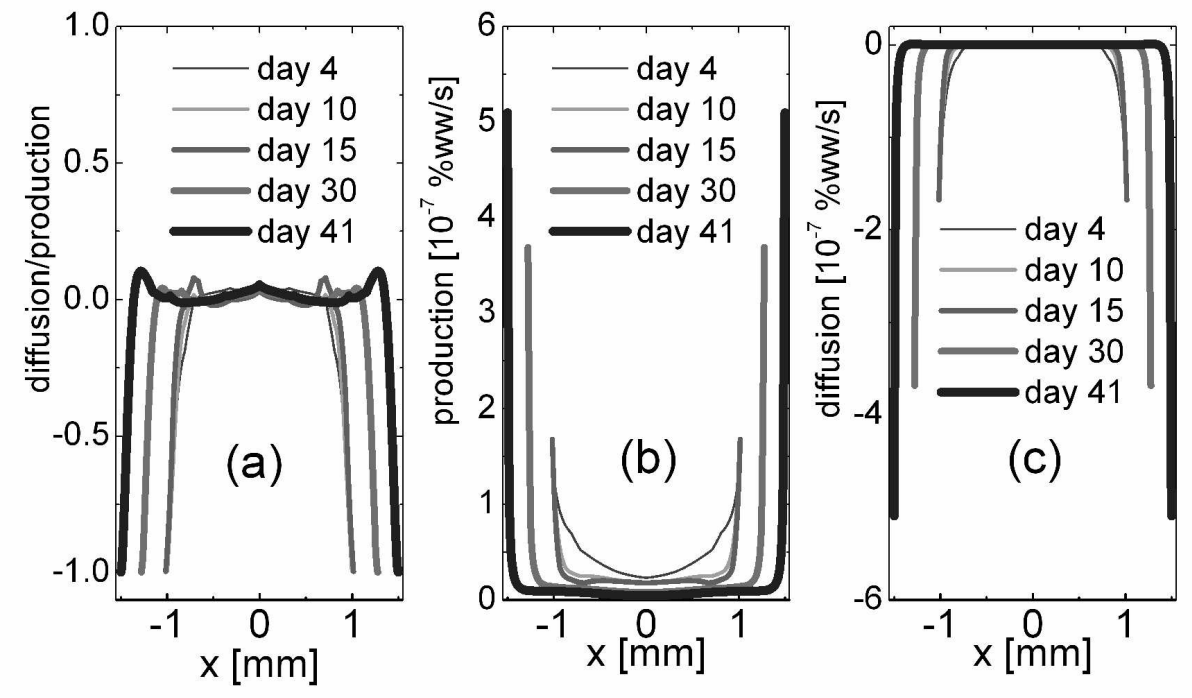

Figure. 5

$317 \times 198 \mathrm{~mm}$ (300 x 300 DPI) 


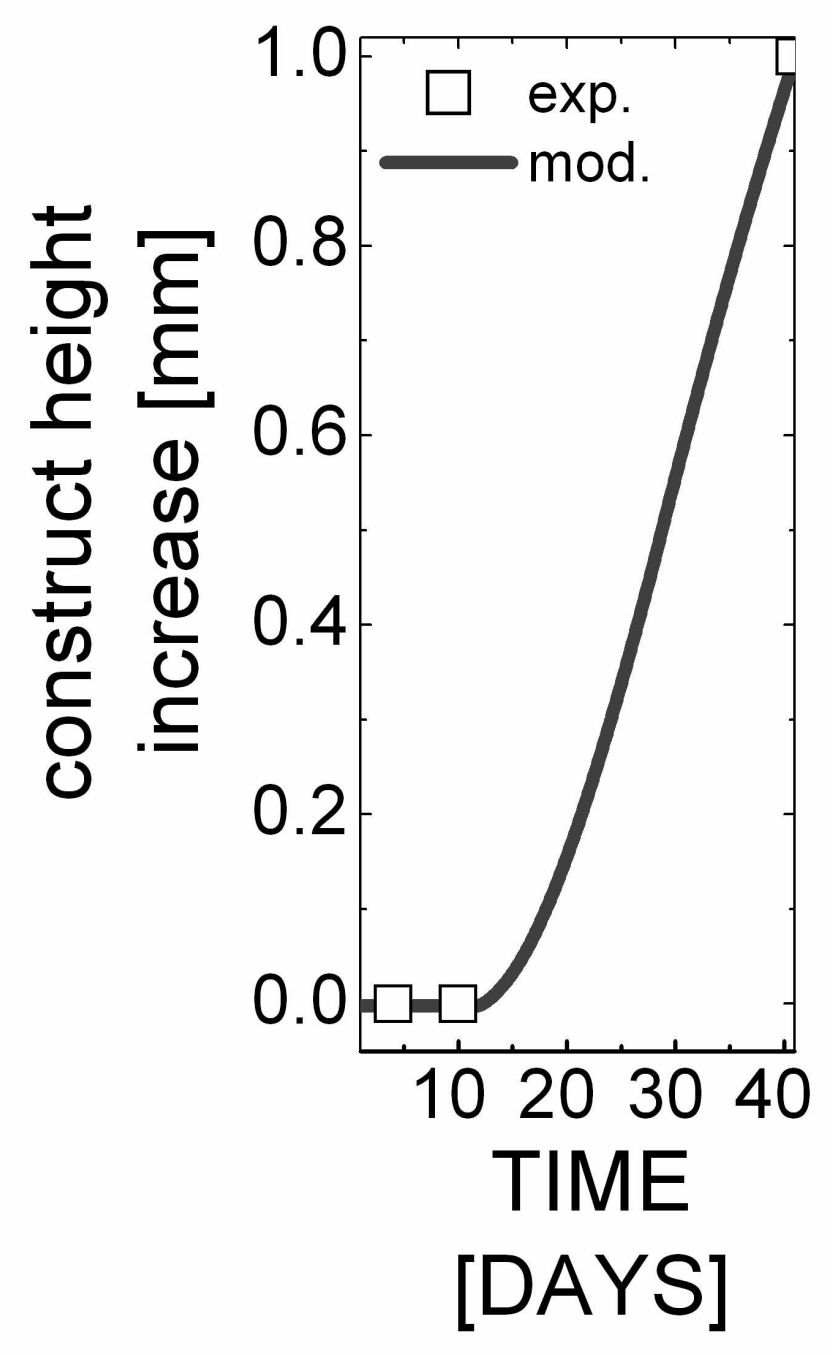

Figure. 6 $143 \times 215 \mathrm{~mm}(300 \times 300$ DPI $)$ 


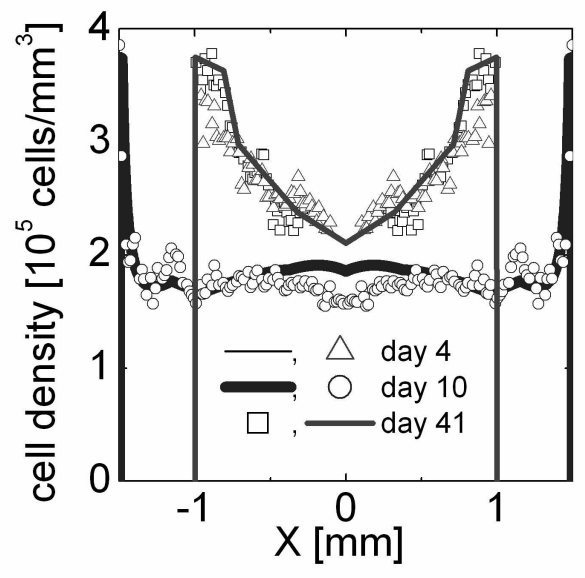

(a) cells

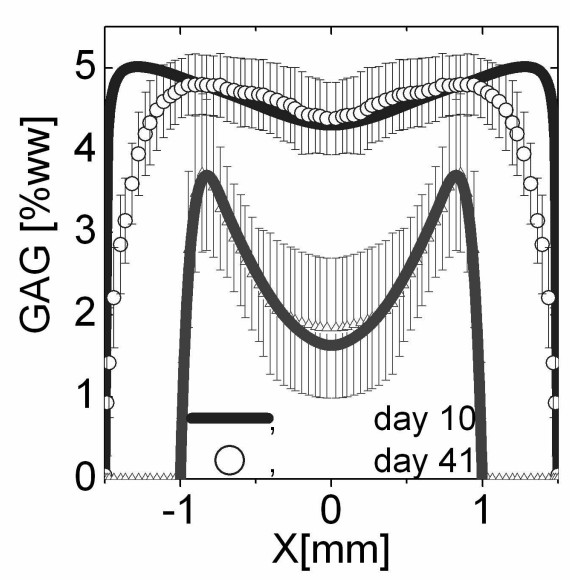

(b) bound GAG

Figure. 7

$258 \times 160 \mathrm{~mm}(300 \times 300 \mathrm{DPI})$ 